\title{
Selective decontamination to reduce gram-negative colonisation and infections after oesophageal resection
}

\author{
GEerT W. M. TET TEROO JOHAN H. T. WAGENVOOR'T \\ allard Castelein Hugo W. Tilanus Can Ince \\ HAJO A. BRUINING
}

181 patients undergoing resection of the oesophagus for carcinoma were randomised to receive selective decontamination (test group) or conventional perioperative antibiotic prophylaxis (controls). 114 patients were finally included in the study: 12 of 56 test patients had 18 infections, whereas 32 of 58 controls acquired 51 infections. Colonisation with aerobic gram-negative microorganisms, and the number of postoperative respiratory tract infections were significantly lower in the test patients. The postoperative therapeutic use of antibiotics was significantly lower in the test group. No endogenous infections were caused by gram-negative bacilli in the test group. Selective decontamination reduces colonisation with gram-negative bacilli and postoperative infections after resection of the oesophagus.

Lancet 1990; 335: 704-07.

\section{Introduction}

Hospital-acquired infections cause substantial morbidity and mortality, especially on surgical wards and intensive therapy units (ITU). ${ }^{1-10}$ Most of these infections are endogenous--ie, they are preceded by colonisation of the gastrointestinal tract and oropharynx by increasingly multiresistant gram-negative bacilli (GNB). ${ }^{2-5,11-14}$ Selective decontamination (SD) is a procedure to eliminate these organisms from the digestive tract leaving the anaerobic flora unaffected. The anaerobes are part of the first-line defence in the gut (colonisation resistance ${ }^{15}$ ), and they play an important part in the prevention of overgrowth of GNB. ${ }^{16}$ Results of earlier trials (in which non-absorbed antibiotics were used) in granulocytopenic patients were promising and use of SD in these patients has been accepted. ${ }^{17,18}$ However, the benefit of modified regimens of $\mathrm{SD}$ in intensive care patients remains controversial. A reduction in infection rate from 81 to $16 \%$ was reported by Stoutenbeek et a ${ }^{19}$ who used SD with systemic cefotaxime in 122 multiple trauma patients with a moderately long ITU-stay ( $\geqslant 5$ days). Ledingham et $a^{20}$ advocate the use of this antibiotic regimen for unselected groups of patients in non-specialised ITUs; they found a 24 to $10 \%$ reduction in acquired infections in patients on a general ITU. A criticism of previous trials is that historical controls and heterogeneous patient-populations were studied. ${ }^{9}$

We here report a prospective, randomised study on the effects of selective decontamination in a homogeneous group of patients undergoing elective oesophageal resection for carcinoma; we chose this group because there is a high frequency of lower respiratory tract infections with GNB due to lower colonisation resistance in such patients.

\section{Patients and methods}

\section{Infection rate}

To estimate the infection rate for oesophageal resection in our hospital before the SD trial, we assessed data from 75 patients ( 54 men, 21 women; mean age 59.5 years, range 39-78) who had had surgery for oesophageal carcinoma in 1985; they had been examined by endoscopy, computed tomography, and ultrasonography. Only patients who had no local ingrowth and no distant metastatic disease were judged to be operable. Since 1983, cefamandole and metronidazole ( $1 \mathrm{~g}$ and $500 \mathrm{mg}$, respectively four times a day, $24 \mathrm{~h}$ perioperatively - ie, $\leqslant 1 \mathrm{~h}$ before until about $24 \mathrm{~h}$ after surgery) were used as prophylaxis in this type of operation. Mean length of time in hospital and ITU was 34 days (range 21-105) and 6.5 days $(1-48)$, respectively. Pneumonia developed in 16 pateints $(21 \%)$, urinary tract infection in $4(5 \%)$, and septicaemia in $5(7 \%) ; 5$ patients $(7 \%)$ died. The infection rate and mortality for the 5 years before the study were similar to those for 1985 (20\% and $5 \%$, respectively).

\section{Patients and controls}

Between March, 1986, and December, 1988, 181 patients who were going to have surgery for oesophageal carcinoma were included in the study. On admission to hospital the patients were randomised (fixed block size, $\mathrm{n}=8$ ) and allocated either to a control group (standard antibiotic prophylaxis) or to a test group (SD medication combined with systemic cefotaxime during the first 4 days). For all patients the bowel was cleared (laxatives and enemas) during the 3 days before surgery. Until November 1986, a combined right-sided thoracotomy and median upper laparotomy was done on the 4 th day. The oesophagus and tumour were mobilised by blunt dissection through a laparotomy incision, and a second incision in the neck was made to complete the oesophagectomy; the upper digestive tract was reconstructed with a tube made from the stomach, or by colonic interposition (table I). The oesophageal resection was an important inclusion-criterium for analysis.

67 patients were excluded from the study because oesophageal resection was not done (tumour not resectable in 42 patients, tumour of cardia not involving the oesophagus in 12); SD medication was discontinued (non-compliance because of taste in 2 ,

ADDRESSES. Departments of Surgery (G. W M. Tetteroo, MD, A Casteleın, MD, $\mathrm{H}$ W Tilanus, MD, $C$ Ince, PhD, Prof $H$. A Bruining, $M D$ ) and Clinical Microbiology ( $J H \quad T$. Wagenvoort, MD) University Hospital Dijkzigt, Erasmus University, Rotterdam, the Netherlands. Correspondence to Prof $H$ A. Bruining 
vomiting and nausea in 4, and allergy in 1); or other antibiotics had been used preoperatively ( 6 patients). Thus, 114 patients ( 56 test group, 58 control group) were studied. The trial was approved by the hospital ethical committee and informed consent was given by the patients.

\section{Specific medication}

SD medication consisted of a sticky ointment ('Orabase', Squibb), containing a mixture of $2 \%$ polymyxin $\mathrm{E}, 2 \%$ tobramycin, and $2 \%$ amphotericin B, applied four times a day on buccal mucosa; a suspension of the same drugs $(200,80,500 \mathrm{mg}$, respectively) was given at $6 \mathrm{~h}$ intervals by mouth, nasogastric tube, or needle jejunostomy. This regimen was started on the day of admission, and was continued until the 10th postoperative day (or longer if infection had not resolved); specific antibiotics were also given. We chose this period because the high risk for aspiration and other respiratory disorders in these patients lessens quickly after 10 days, as we had previously experienced. Systemic cefotaxime $(1 \mathrm{~g}$, four times a day) was added as supplementary prophylaxis for the first 3 days before surgery (SD is not yet fully established during this time), and was discontinued after surgery (day +1$)$. On the day of surgery, systemic metronidazole (500 $\mathrm{mg}$, four times a day) is added as part of the usual $(24 \mathrm{~h})$ prophylaxis in bowel surgery. Antibiotic prophylaxis in the control group consisted of cefamandole and metronidazole ( $1 \mathrm{~g}$ and $500 \mathrm{mg}$, respectively, four times a day), both given systemically for $24 \mathrm{~h}$ perioperatively.

To assess the effect of this new antibiotic prophylaxis on the possible development of resistance, we recorded all resistant strains and compared the two groups.

\section{Bacteriology}

Cultures from nose, throat, sputum (when present), urine, and faeces (or rectal swab) were taken on admission, and thereafter three times a week. Drains, gastric contents, and feeding fistulae were also cultured. Identification of pathogenic microorganisms and antibiotic sensitivity tests were done according to usual laboratory techniques. We defined primary infections as those that developed within $48 \mathrm{~h}$ of admission; they are mostly caused by communityacquired gram-positive microorganisms. Secondary infections, were those that arose $48 \mathrm{~h}$ after hospital admission and we assumed that these were hospital acquired; they are mostly caused by gram-negative microorganisms.

\section{Follow-up}

All patients were examined daily for clinical signs of infection during their admission; diagnosis of infection was confirmed by culture. Chest radiographs were taken daily during the first 3 postoperative days and thereafter if clinically indicated. Radiographs were judged by the same radiologist and chest physician each time, both of whom were unaware of the group that the patients had been allocated to. When a lower respiratory tract infection was suspected cultures from lobular aspirations were taken by bronchoscopy. In both groups treatment was only started when there was clinical and microbiological evidence of infection. Antibiotics were chosen according to hospital guidelines based on the sensitivity patterns of the isolated organisms. In the test patients, antibiotics that would not affect colonisation resistance were given. None of the patients was given $\mathrm{H}_{2}$-blockers.

\section{Statistical analysis}

To detect a significant reduction in postoperative infections, 56 patients were needed in each group, with $\alpha$ and $\beta$ at 0.05 (based on the infection rate for oesophageal resection before the study). The $\chi^{2}$ square test (with Yates' correction) and Fisher's exact test were used to compare frequencies. To compare the number of infections and non-infectious complications, we used the Mann-Whitney test. A p value of 0.05 or less (Fisher, 0.025) was regarded as significant.

\section{Results}

Table I shows that the two groups were broadly similar. To exclude any influence of a change in surgical technique on infection rates, we analysed all infections in patients who had had a thoracotomy $(n=36)$ and in those who had not had a thoracotomy $(n=78)$. Infections developed in $13(36 \%)$ and 33 patients $(42 \%)$, respectively; lower respiratory tract infections developed in 5 and 8 patients, respectively. These differences were non-significant.

\section{Colonisation rates}

On the day of surgery, colonisation of the oropharynx, rectum and urinary tract with potentially pathogenic microorganisms was recorded in $7 \%, 11 \%$, and $2 \%$ of test patients, respectively. The overall colonisation rate with aerobic GNB decreased significantly in test patients during the first 10 postoperative days (table II).

\section{Infection rates}

During the first 10 postoperative days, 32 controls had 51 infections whereas 12 test patients acquired 18 infections $(\mathrm{p}<0.001)$; there were significantly fewer respiratory tract infections and minor wound infections in the test patients (table II). All infections were secondary, except for 2 urinary tract infections on admission, which were not included in this analysis. Most infections were endogenous (test group $83 \%$, controls $73 \%$ ). In the control group 54\% (46/85) of the causative microorganisms were GNB (Pseudomonas sp, Proteus sp, Klebsiella sp, Enterobacter sp, Acinetobacter sp, Citrobacter sp, and Escherichia coli), 41\% (35/85) were gram-positive cocci (Staphylococcus epidermidis, $S$ aureus,

TABLE I-PATIENT CHARACTERISTICS

\begin{tabular}{l|c|c}
\hline \multicolumn{1}{c|}{ Characteristic } & Test $(\mathrm{n}=56)$ & Control $(\mathrm{n}=56)$ \\
\hline Sex $(M / F)$ & $35 / 21$ & $42 / 16$ \\
Age range (mean) (yr) & $40-77(60)$ & $42-78(60 \cdot 6)$ \\
Cardiac history & 4 & 10 \\
Pulmonary disease & 8 & 7 \\
Preoperative irradiation & 30 & 33 \\
Surgical technique (no) & $18(32 \%)$ & $18(31 \%)$ \\
Thoracotomy & 50 & 51 \\
Stomach tube & 4 & 4 \\
Colonic interposition & 2 & 3 \\
Jejunal interposition & $7(12 \%)$ & $7(12 \%)$ \\
No of reinterventions & $1-99(5 \cdot 5)$ & $0-35(4 \cdot 9)$ \\
Admission (no of days) & 310 & 286 \\
ITU stay/patient (range) (mean) & $14-103(25 \cdot 6)$ & $11-91(27 \cdot 7)$ \\
ITU stay/group & 1434 & 1608 \\
Hospital stay/patient (range) (mean) & 3 & 2 \\
Hospital stay/group & 3 & \\
Mortality & &
\end{tabular}

TABLE II-COLONISATION DURING THE FIRST 10 POSTOPERATIVE DAYS

\begin{tabular}{l|c|c|c|c|c|c}
\hline \multirow{2}{*}{ Site } & \multicolumn{5}{|c|}{ No of patients colonised (\%) } \\
\cline { 2 - 7 } & \multicolumn{3}{|c|}{ Test $(n=56)$} & \multicolumn{2}{c}{ Control $(n=58)$} \\
\cline { 2 - 7 } & Gram + & Gram - & Total & Gram + & Gram - * & Total \\
\hline $\begin{array}{l}\text { Gastrointestinal } \\
\text { tract }\end{array}$ & $28(50)$ & $3(5)$ & $28(50)$ & $51(94)$ & $41(76)$ & $58(100)$ \\
$\begin{array}{l}\text { Respiratory } \\
\text { tract }\end{array}$ & $26(46)$ & $4(7)$ & $26(46)$ & $36(67)$ & $44(81)$ & $50(86)$ \\
Urinary tract & $30(54)$ & $5(9)$ & $30(54)$ & $48(99)$ & $47(87)$ & $48(89)$ \\
\hline
\end{tabular}

$\star_{\mathrm{p}}<001\left(\alpha^{2}\right.$ test) for comparison between test patients and controls 
TABLE III-ACQUIRED INFECTIONS WITHIN FIRST 10 POSTOPERATIVE DAYS

\begin{tabular}{|c|c|c|c|c|c|c|c|c|}
\hline \multirow[b]{2}{*}{ Infection } & \multicolumn{4}{|c|}{ No of test patients $(n=56)$} & \multicolumn{4}{|c|}{ No of controls $(n=58)$} \\
\hline & Gram + & Gram- & Mixed & Total & Gram + & Gram - & Mixed & Total \\
\hline $\begin{array}{l}\text { Pulmonary } \\
\text { Urinary tract } \\
\text { Wound } \\
\text { Septicaemia } \\
\text { Other }\end{array}$ & $\begin{array}{l}1 \\
3 \\
6 \\
1 \\
5\end{array}$ & $\begin{array}{l}0 \\
2 \S \\
0 \\
0 \\
0\end{array}$ & $\begin{array}{l}0 \\
0 \\
0 \\
0 \\
0\end{array}$ & $\begin{array}{l}1(2 \%) \\
5(9 \%) \\
6(11 \%) \\
1(2 \%) \\
5(9 \%)\end{array}$ & $\begin{array}{l}2 \\
4 \\
9 \\
1 \\
3\end{array}$ & $\begin{array}{l}4 \\
7 \\
5 \\
0 \\
2\end{array}$ & $\begin{array}{l}2 \\
2 \\
6 \\
0 \\
4\end{array}$ & $\begin{array}{l}8(14 \%) \star \\
13(22 \%) \\
20(35 \%) \dagger \\
1(2 \%) \\
9(15 \%)\end{array}$ \\
\hline Total & $16(89 \%)$ & $2(11 \%) \ddagger$ & 0 & 18 & $19(37 \%)$ & $18(35 \%)$ 丮 & $14(27 \%)$ & 51 \\
\hline
\end{tabular}

$\star<0.05, t p<001$, and $\neq p<0001$ for controls vs test patients

$\$$ Not preceded by colonisation, 4 causative organisms

and Enterococcus sp) and 5\% (4/85) were gram-negative diplococci (Neisseria sp and Branhamella $\mathrm{sp}$ ). By contrast, in test patients GNB (Pseudomonas sp, Acinetobacter sp, and $E$ coli) accounted for $15 \%(4 / 27)$ of infections and gram-positive cocci for $85 \%$ ( $p<0.001$, table III). 12 new infections arose in 4 test patients after SD treatment was stopped at 10 days: 3 were respiratory tract infections. 2 patients had not had a previous infection, but were heavily colonised with GNB after SD medication was discontinued. Half the infections were gram-negative or mixed. 1 pulmonary tract infection, caused by GNB, developed in a control patient. There was no increase in antibiotic resistance.

In a small subgroup of patients $(n=26)$, who stayed for more than 4 days on the ITU, the reduction in infectious complications and the number of respiratory tract infections after SD, was not significant. 5 controls got respiratory tract infections compared with 1 test patient. The therapeutic use of antibiotics postoperatively was significantly different in the two groups; 25 controls and 11 test patients needed specific antibiotics $\left(p=0.013, \chi^{2}\right.$ test). During this study until July 1988, 1 test patient was colonised with a resistant strain of Acinetobacter; 2 controls were colonised, 1 with a resistant Pseudemonas strain, and the other with a resistant Acinetobacter strain. 3 test patients died (5\%); in 2, infections were contributory factors. In the control group, 2 patients $(3 \%)$ died of non-infectious causes.

\section{Discussion}

We have shown that SD reduces postoperative infections caused by GNB after oesophageal resection and one-stage reconstruction. Factors that may have influenced infection rates, such as a thoracotomy or colon interposition were equally distributed among both groups; moreover, there were no significant differences in postoperative infectious complications for the two surgical procedures.

Between 1983 and the beginning of our study the systemic prophylaxis indicated in this kind of operation ${ }^{21}$ was cefamandole and metronidazole, $24 \mathrm{~h}$ perioperatively. We decided to give the same systemic prophylaxis to the control group to detect any influences on infection rates, even though a different medication strategy was given to test patients-namely, cefotaxime and metronidazole. We did not expect the results to be influenced by this difference because cefotaxime was used only pre-operatively and during the first $24 \mathrm{~h}$ postoperatively, and cefamandole was given to control patients for $24 \mathrm{~h}$ perioperatively. Mandelli and colleagues ${ }^{22}$ did not find an effect of systemic prophylaxis on the occurrence of early onset pneumonia in patients in the ITU. Moreover, since the half-life of cefotaxime does not exceed $1 \mathrm{~h},{ }^{23}$ we believe that the influence of this drug on outcome was negligible. For better comparability, metronidazole was given systemically to both groups: the anaerobic gut flora are not affected because intraluminal concentrations are too low. ${ }^{24}$

We did not do a double-blind study because knowledge of culture results was essential to the physicians in charge of the patients, and because surveillance cultures are an important part of SD. The number of gram-positive infections in the control group was striking, and indicates how important such cultures are, since gram-positive organisms are not eliminated by SD. Cultures are also necessary to detect the development of resistance during the use of antibiotics. The reason why the number of urinary tract infections was non-significantly reduced with SD prophylaxis was probably because most nosocomial urinary tract infections are associated with instrumentation ${ }^{25}$ and all of our patients had indwelling urinary catheters.

That patients were rapidly colonised by GNB after discontinuation of SD medication points to a protective influence of SD, and suggests that SD prophylaxis in these patients should be continued. We cannot comment about a possible effect of SD on mortality because of the low mortality rate in this group of patients.

Although the reduction in infection rate led to a significant reduction in therapeutic use of antibiotics in the test group, this reduction did not influence the length of admission as noted by others. ${ }^{5.9}$ However, for how long a patient stays in hospital depends on surgical complications which were equally distributed in both groups. Although we could not show a beneficial influence of SD in those staying for more than 4 days in the ITU, there was a substantial reduction in the number of respiratory tract infections in this small group who are highly susceptible to gram-negative bacterial infections. ${ }^{2-4,7.8}$

We thank the nursing staff of our wards and ITU for their cooperation in the study, and Dr M. Meyssen, and Dr M. Menu for their help in collecting th data. We also thank Mrs C. Vollebregt, Mr K. Jongkind, Mr A. Boogaart, anc Mr P. Mulder (department of biostatistics) for statistical analyses.

This study was financially supported by Eli Lilly and Roussel B.V., the Netherlands.

\section{REFERENCES}

1. Caplan ES, Hoyt N. Infection surveillance and control in the severel traumatized patient. Am $\mathcal{F}$ Med 1981; 70: 638 .

2. Northey ML, Adess JM, Hartsuck JM, Rhoades ER. Microbi surveillance in a surgical intensive care unit. Surg Gynecol Obstet 1974 139: $321-25$.

3. Eickhoff TC. Nosocomial infections. N Engl f Med 1982; 306: 1545-46

4. Daschner FD. Nosocomial infections in intensive care units. Intensiz Care Med 1985; 11: 284-87. 
5. Craven DE, Kunches LM, Kilinsky V, Lichtenberg DA, Make BJ, McCabe WR. Risk factors for pneumonia and fatality in patients receiving continuous mechanical ventilation. Am Rev Resp Dis 1986; 133: 792-96.

6. Donowitz LG, Wenzel RP, Hoyt JW. High risk of hospital acquired infection in the ICU-patient. Crit Care Med 1982; 10: 355-57.

7. Kerver AJH, Rommes JH, Mevissen-Verhage EAE, et al. Colonization and infection in surgical intensive care patients, a prospective study. Intensive Care Med 1987; 13: 347-51.

8. Kerver AJH, Rommes JH, Mevissen-Verhage EAE, et al. Prevention of colonization and infection in critically ill patients, a prospective randomised study. Crit Care Med 1988; 16: 1087-93.

9. Hughes JM. Epidemiology and prevention of nosocomical pneumonia. In: Remington JS, Schwartz MM, eds. Current clinical topics in infectious diseases. Vol 9. New York: McGraw-Hill, 1988: 241-59.

10. Gross PA, Neu HC, Aswapokee P, van Antwerpen C, Aswapokee N. Deaths from nosocomial infections: experience in a university hospital and a community hospital. Am f Med 1980; 68: 219-23.

11. Bryant LR, Kent Trinkle J, Mobin-Uddin K, Baker J, Griffen WO. Bacterial colonization profile with tracheal intubation and mechanical ventilation. Arch Surg 1972; 104: 647-51.

12. Rose HD, Babcock JB. Colonization of intensive care unit patients with gram-negative bacilli. Am f Epidemiol 1975; 101: 495-501.

13. Chow AW, Taylor PhR, Yoshikawa ThT, Guze LB. A nosocomial outbreak of infections due to multiple resistant Proteus mirabilis: role of intestinal colonization as a major reservoir. $\mathcal{F}$ Infect Dis 1979; 139: $621-27$.

14. Uffelen R van, van Saene HKF, Fidler V, Lowenberg A. Oropharyngeal flora as a source of bacteria colonising the lower airways in patients on artificial ventilation. Intensive Care Med 1984; 10: 233-37.

15. van der Waay D, Berghuis-de Vries JM, Lekkerkerk-van der Wees JEC Colonization resistance of the digestive tract in conventional and antibiotic treated mice. $\mathcal{F}$ Hyg Camb 1971; 69: 405.
16. van der Waay $D$. The digestive tract in immunocompromised patients; importance of maintaining its resistance to colonisation, especially in hospital in-patients and those taking antibiotics. Antonie Van Leeuwenhoek 1984; 50: 745-61.

17. Sleyfer DT, Mulder NH, Vries-Hospers $\mathrm{HG}$ de, et al. Infectionprevention in granulocytopenic patients by selective decontamination of the digestive tract. Eur $\mathcal{F}$ Cancer 1980; 16: 859-69.

18. Guiot HFL, van der Meer JW, van Furth R. Selective antimicrobial modulation of human microbial flora; infection prevention in patients with decreased host-defence mechanisms by selective elimination of potentially pathogenic bacteria. F Infect Dis 1981; 143: 644-54.

19. Stoutenbeek ChP, van Saene HKF, Miranda DR, Zandstra DF. The effect of selective decontamination of the digestive tract on colonization and infection rate in multiple trauma patients. Intensive Care Med 1984; 10: $185-92$.

20. Ledingham IMcA, Eastaway AT, McKay IC, Alcock SR, McDonald JC, Ramsey G. Triple regimen of selective decontamination of the digestive tract, systemic cefotaxime and microbiological surveillance for prevention of acquired infection in intensive care. Lancet 1988; i: $785-90$.

21. Guglielmo BJ, Hohn DC, Koo PJ, Hunt ThK, Sweet RL, Conte JE. Antibiotic prophylaxis in surgical procedures. Arch Surg 1983; 118: 943-55.

22. Mandelli $M$, Mosconi $P$, Langer $M$, Cigada $M$. Intensive care unit group of infection-control. Prevention of pneumonia in an intensive care unit. A randomized multicenter clinical trial. Crt Care Med 1989; 17: 501-05.

23. Donowitz GR, Mandell GL. Beta-lactam antibiotics: second of two parts. $N$ Engl f Med 1988; 318: 490-500.

24. Nord CE, Kager L, Heimdahl A. Impact of antimicrobial agents on the gastrointestinal microflora and the risk of infections. Am $\mathscr{\mathcal { J }}$ Med 1984; 76 (suppl 5a): 99-106.

25. Turck M, Stamm W. Nosocomial infection of the urinary tract. $A m \mathcal{F}$ Med 1981; 70: 651-54.

\title{
MODERN VACCINES
}

\section{Immunisation practice in developed countries}

\author{
ALAN R. HiNMAN WALTER A. ORENSTEIN
}

Successful immunisation programmes require both effective vaccines and effective systems to deliver them. Developed countries, with their good access to target populations, have often led the way; but even some of these show unacceptably high morbidity from conditions preventable by vaccines. This paper will focus on practice in the thirty-two countries of the European Region of the World Health Organisation (WHO), in North America, in Japan, and in Australia. ${ }^{1-6}$

Most countries have their vaccine policies set by central government, often in consultation with the private sector. In the United States, for example, the US Public Health Service has an Immunization Practices Advisory Committee (ACIP) which develops recommendations for vaccine use, primarily aiming at the public sector. ${ }^{7}$ To ensure coordination with the private sector, the ACIP works closely with the Committee on Infectious Diseases of the
American Academy of Pediatrics ${ }^{8}$ and the Task Force on Immunization of the American College of Physicians. ${ }^{9} \mathrm{By}$ contrast, in the Federal Republic of Germany there is strong local autonomy, with some physicians using a particular vaccine (eg, pertussis) and others not. ${ }^{10}$

\section{The vaccines in use}

Almost all the countries under consideration now routinely give DPT (diphtheria and tetanus toxoids and pertussis vaccine), poliomyelitis vaccine (whether oral live attenuated

ADDRESS. Center for Prevention Services, Centers for Disease Control, Atlanta, GA 30333, USA (A. R Hinman, MD, W. A. Orenstein, MD) 